Original Research Paper

\title{
A Computational Investigation into the Effect of Equal Channel Angular Processing on the Mechanical Properties of Severely Deformed ZK 60 Alloy Validated by Experiments
}

\author{
${ }^{1}$ Omar Almenaif, ${ }^{1}$ Yaqoub Alhumaydani, ${ }^{1}$ Mohammed Alnafisah, \\ ${ }^{1}$ Mansour Aldhalaan, ${ }^{1}$ A.I. Alateyah and ${ }^{1,2 *}$ W.H. El-Garaihy \\ ${ }^{1}$ Department of Mechanical Engineering, College of Engineering, Qassim University, Unaizah, Saudi Arabia \\ ${ }^{2}$ Department of Mechanical Engineering, Faculty of Engineering, Suez Canal University, Egypt
}

\author{
Article history \\ Received: 09-05-2020 \\ Revised: 28-05-2020 \\ Accepted: 08-06-2020 \\ Corresponding Author: \\ W.H. El-Garaihy \\ Department of Mechanical \\ Engineering, College of \\ Engineering, Qassim \\ University, Unaizah, Saudi \\ Arabia \\ And \\ Department of Mechanical \\ Engineering, Faculty of \\ Engineering, Suez Canal \\ University, Egypt \\ Email: W.Nasr@qu.edu.sa
}

\begin{abstract}
In this study, the response surface method and finite-element analysis were employed to model the ECAP processing for biodegradable magnesium alloy $\mathrm{ZK} 60$ behavior at $250^{\circ} \mathrm{C}$. Using Finite-Element (FE) analysis data was extracted and compared to the what was found by experimenting in order to investigate the effects of the ECAP processing parameters on the plastic deformation behavior of the ECAPed samples. The effective strain and stresses as a function of the number of passes were investigated. Hardness contour maps perpendicular to ECAP direction were plotted. Compressive properties of the billets were also examined. The FE analysis revealed that the maximum stresses were displayed at the corner and peripheral areas compared to the central areas. Moreover, straining through two passes of route $\mathrm{Bc}$ displayed maximum effective strain of 2.75 recorded in the top peripheral regions, whereas the central regions displayed 1.25. In addition, ECAP processing via $2-\mathrm{Bc}$ correlated with rises in $\mathrm{Hv}$ values in the samples peripheries by $125.4 \%$ respectively, when compared with the as-annealed conditions. The compression findings showed also significant enhancement of the compressive strength compared to the as-annealed counterparts.
\end{abstract}

Keywords: ECAP, SPD, ZK 60, Hardness Homogeneity, Effective Strain Distribution

\section{Introduction}

With the evolving world and the enhancement in the living standards; the standards expected from medical care were raised, with people expecting better medical care. Therefore, in order to achieve that; researchers started searching on Biodegradable Metals (BMs) which are a new category of biomedical material. However, BMs are metals that gradually corrode in vivo as expected of materials inserted to the body. Moreover, these metals assist the healing process of tissues and they dissolve completely during the process. Therefore, biodegradable metals should be carefully selected such that they are not toxic and show an appropriate degradation rate (Mostaed et al., 2014; Orlov et al., 2011).

Magnesium is a considerable contender in biomedical applications because of its unique mechanical properties that resembles human bones (Aung and Zhou, 2010). Moreover, Magnesium is considered one of the seven important minerals required for the maintenance of a healthy body and it is located in human tissue naturally (Valiev and Langdon, 2006; Yamashita et al., 2001). Mg is also an extremely lightweight metal with a density of $1.74-2.0 \mathrm{~g} / \mathrm{cm}^{3}$ whereas human bones have a density of $1.8-2.1 \mathrm{~g} / \mathrm{cm}^{3}$ (Yamashita et al., 2001). $\mathrm{Mg}$ is a highly corrosive metal with a negative electrode potential of -2.363 V (Alvarez-Lopez, 2010). In addition, when used to aid in tissue recovery and recovery $\mathrm{Mg}$ is less invasive even offering temporary support and it gradually dissolves or is absorbed by the body afterwards (Zhang et al., 2016). Therefore, $\mathrm{Mg}$ is a degradable metal that leads to elimination of the post-surgery (Ge et al., 2013). It is worth to mentioning here that, the major bottlenecks for using $\mathrm{Mg}$ as appropriate selection in biomedical applications is the metal's poor corrosion resistance, its underwhelming ductility and its relatively low strength, which have always been an obstacle to the community in the development of $\mathrm{Mg}$ technology (Hu et al., 2017). The poor ductility of $\mathrm{Mg}$ is resultant from its hexagonal closed packed crystal structure, 
which lacks sufficient independent slip systems to accommodate the global strain (Zhu and Huang, 2001).

However, the most prominent issue with pure $\mathrm{Mg}$ is its low corrosion resistance that leads to fast and undesirable degradation. Therefore, one way to overcome the corrosion problem is alloying elements with changeable concentrations which can be added to pure $\mathrm{Mg}$ to enhance its mechanical properties as well as its corrosion behavior (Ge et al., 2013).

In selecting the alloying elements, the main focus should be the enhancement of the mechanical properties as well as the biocompatibility of the $\mathrm{Mg}$. Improving the strength of $\mathrm{Mg}$ by adding the alloying elements can be done by means of solid solution strengthening and grain refinement (Valiev and Langdon, 2006). However, some investigations were conducted on $\mathrm{Mg}$ alloys that contain alloying elements such as $\mathrm{Al}$ and rare-earth element and they both showed toxicity. For instance, Al might leads to Alzheimer's disease whereas yttrium might cause liver toxicity (Miyamoto et al., 2008).

Moreover, Zinc (Zn) is considered a suitable alloying element in biodegradable magnesium alloys ( $\mathrm{Hu}$ et al., 2017), because it is found in the human body's tissues and it is one of the most abundant nutrition elements/Minerals in the human body. Moreover, $\mathrm{Zn}$ is soluble in $\mathrm{Mg}$ in quantities up to $6.2 \mathrm{wt}$ \% (Song et al., 2019; Li et al., 2011). $\mathrm{Zn}$ improves the mechanical properties of $\mathrm{Mg}$, its corrosion behavior and its ductility (Zhu and Huang, 2001; Tong et al., 2010). In addition, (Ding et al., 2010) found that the addition of zirconium reduces the corrosion rate and improves the strength of magnesium. Therefore, the ZK 60 alloy was chosen to be investigated in this research based on the information provided.

The grain refinement process achieved by Severe Plastic Deformation (SPD) techniques is an appropriate method used to improve both the mechanical and corrosion properties of $\mathrm{Mg}$ alloys as a result of HallPetch strengthening and the homogeneous distribution of precipitates, respectively (Mostaed et al., 2014; Orlov et al., 2011; Aung and Zhou, 2010; Valiev and Langdon, 2006; Yamashita et al., 2001; Alvarez-Lopez, 2010; Ge et al., 2013). SPD is a metal forming process where a very high strain is forced on a bulk solid without changing the overall dimensions of the solid which leads to an exceptional grain refinement (Valiev and Langdon, 2006). SPD techniques are some of the most successful techniques in refining existing materials into nanostructured materials (Zhu and Huang, 2001). It is worth mentioning here that the utilization of SPD techniques leads to grain refinement and to the break-up of second-phase particles which improves corrosion resistance (Qiang et al., 2014).

One of the modern SPD techniques that reduce the grain size to sub-microcrystalline scale $(0.1-0.2 \mu \mathrm{m})$ is Equal Channel Angular Pressing (ECAP) process (Zhu and Huang, 2001; El Garaihy, 2020). In recent years, the results of the ECAP on $\mathrm{Mg}$ alloys have been investigated. However, those studies generally focus on mechanical properties (Mostaed et al., 2014; Yamashita et al., 2001; Li et al., 2011; Tong et al., 2010; Ding et al., 2010). In ECAP process, a billet is extruded through a die with two channels intersecting at an die angle $\Phi$ and with an angle of curvature $\psi$ (Shaeri et al., 2019; Nassef et al., 2015). The common routes are: Route $\mathrm{A}$, with no billet rotating between subsequent passes; route $\mathrm{B}_{\mathrm{A}}$, the sample is rotated $90^{\circ}$ clockwise and counterclockwise in alternate passes; route $\mathrm{B}_{\mathrm{c}}$ with billet rotating $90^{\circ}$ between the subsequent passes; and route $\mathrm{C}$, the sample is rotated $180^{\circ}$ (Nassef et al., 2015; Wang et al., 2019). Among the different ECAP routes, route $\mathrm{B}_{\mathrm{c}}$ can be considered as the most effective route for grain refinement, whereas both route $A$ and $B_{c}$ are the most effective routes for improving the mechanical properties (Tong et al., 2010; Howeyze et al., 2018). In ECAP process, the equivalent strain imposed to the billet can be calculated from the following relationship (Priela et al., 2019):

$\varepsilon e q=\frac{N}{\sqrt{3}}\left[2 \cot \left(\frac{\varphi+\psi}{2}\right)+\psi \operatorname{cosec}\left(\frac{\varphi+\psi}{2}\right)\right]$

This study was instigated to determine the effects of ECAP processing on the mechanical properties of biodegradable ZK 60. Accordingly, the aim of this study is to provide a more detailed mapping of the ECAP process through numerical modeling to study the effective induced stress-strain behaviors and their distribution after multiple passes of ECAP processing. The veracity of the numerical model is gauged by investigating the hardness distribution across the sample's transverse section and its compressive properties after deformation.

\section{Simulation and Numerical Modeling}

Finite Element (FE) analysis was performed to display the imposed strain and stress distribution during ECAP processing. In addition, the $\mathrm{FE}$ analysis parameters were examined side by side with compared to the experimental geometries in order to investigate the effects of the geometric, material and process parameters on the plastic deformation behavior of the magnesium alloy billet during the ECAP process.

To simulate the ECAP process, the cold forming extrusion module was used. The model consisted of the plunger, the 2-halves of the ECAP die and the ECAPed billets. For clarity and improved visualization, all parts were invisible apart from the billet during simulation. The 2halves die, plunger and billet were modeled as a rigid body made of an imaginary non-formable material. The Magnesium alloy ZK 60 was selected from the built-in library as the material of the work-piece. The mechanical and thermal properties were pre-described. Furthermore, hexahedral mesh, typically used to model 3-Dimensional 
(3D) regular shapes, was used with mesh size of $0.5 \mathrm{~mm}$ which yielded a total number of nodes of 9500 to 15000 elements depending on specimen's degree of distortion which increased in each pass. The ECAPed material was modeled as an isotropic linear elastic and strain hardenable rigid plastic material. Tracked elements were located at the plane in the middle of the specimen at the edge where max strain occurs and at the center where SPD has the lowest effect. Ram speed was adopted to be $0.05 \mathrm{~mm} / \mathrm{s}$. Coulomb friction model was used with die friction factor 0.05 .

\section{Experimental Procedure}

The experimental procedures and tests were conducted using a ZK 60 biodegradable magnesium alloy. ZK 60 billets were received in the form of long billets with a diameter of $20 \mathrm{~mm}$ and a length of $50 \mathrm{~cm}$. The ZK 60 billets were sectioned into ECAPed samples of $50 \mathrm{~mm}$ length and $20 \mathrm{~mm}$ diameter to be used in further investigations using a high precision cutting Machine (METACUT 302). ECAP processing was conducted through 1 pass (1-P) and 2 passes of route $B_{c}$ (2-Bc) at $250^{\circ} \mathrm{C}$ using a $100 \mathrm{kN}$ universal testing machine under a constant ram speed of $10 \mathrm{~mm} / \mathrm{min}$. For homogenization of the microstructure, the samples were annealed at $430^{\circ} \mathrm{C}$ for 16 hours followed by furnace cooling. In this study, a 2-half ECAP die was manufactured from high strength steel (W302) as shown in Fig. 1. The ECAP die channels intersect at a die angle of $\varphi=90^{\circ}$ with an angle of curvature $\psi=$ $20^{\circ}$ which imparts an equivalent strain of about 1.05 per pass according to Equation 1. The billets were lubricated using a graphite-based lubricant and pressed into the ECAP die.

After the ECAP process, the billets were polished to a mirror like finish. Vicker's micro hardness (Hv) values were measured from the ECAPed billets' centers to the peripheries of the billets' transverse sections of the top part of the ECAPed samples to assess the hardness variation along the ECAPed billets. The hardness test was carried out under an applied load of $1 \mathrm{~kg}$ for $15 \mathrm{~s}$. Individual values of $\mathrm{Hv}$ were recorded across the diameter of each aforementioned part in the billet in incremental steps of $0.5 \mathrm{~mm}$. The results were presented after an average was taken from them with a minimum of three indentations per site. Additionally, the microhardness profiles and the extent of homogeneity were illustrated by color-coded outlines created to display the hardness distribution along the transverse and longitudinal directions of the ECAPed samples.

The compressive properties of the extruded billets were studied using cylindrical samples with a $20 \mathrm{~mm}$ diameter and $30 \mathrm{~mm}$ long. Compression samples were processed by machining according to the American Society for Testing of Materials' (ASTM/E9) standards for short specimens with a Length to Diameter ratio $(L / D$ ratio) of 1.5. A minimum of three samples were tested per condition. Compression test was conducted on a 100 $\mathrm{kN}$ universal testing machine. The ZK 60 billets were tested before and after ECAP processing at a strain rate of $1 \times 10^{-3} \mathrm{~S}^{-1}$ at room temperature.

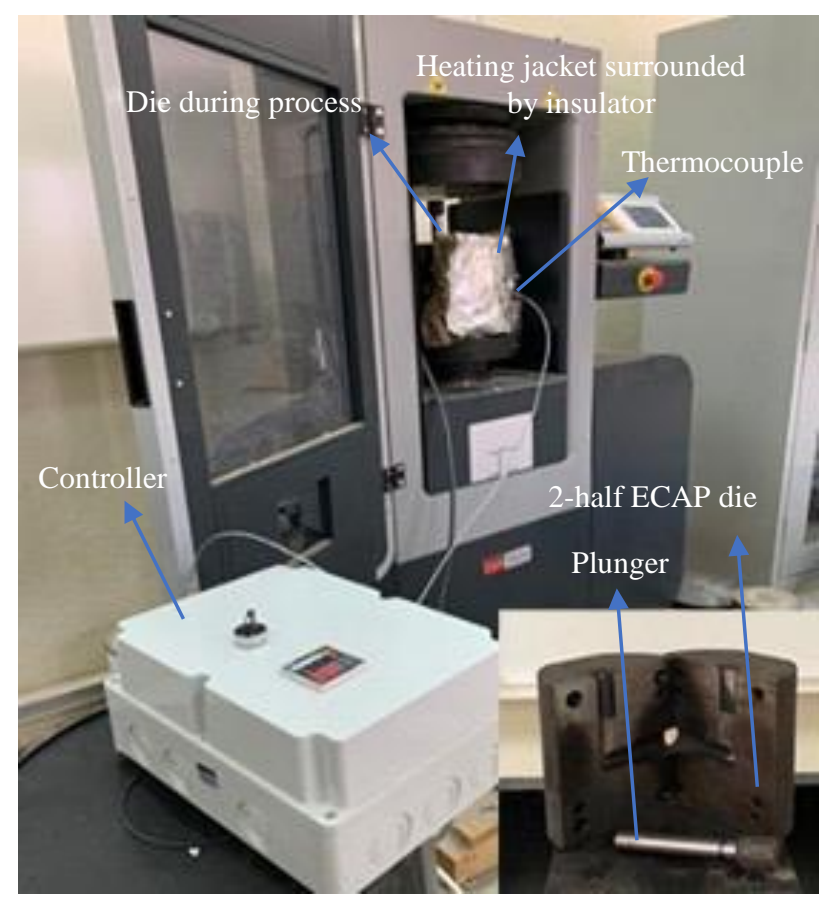

Fig. 1: Micrograph of the 2-halfes ECAP die 


\section{Results and Discussion}

\section{Numerical Analysis}

Figure 2 shows the effective stresses distribution contours and a sectional view of the stresses distribution for the ECAPed specimens processed via 1-P and 2-Bc, coupled with a sectional view of the stress distribution along the longitudinal and transverse sections. Similar displays of the strains distribution for the ECAPed samples processed via 1-P and 2-Bc are shown in Fig. 3. The plunger and die have been removed for better visualization and depiction. As shown in Fig. 2a to 2c, the maximum stresses of the corner and the peripheral areas are displayed, compared with the central areas. This could be due to the specimen contacting the applied pushing force from the plunger, which yielded comparably higher $\mathrm{Hv}$ values at the top part. Accordingly, Fig. 2c shows the processed billet after processing via 1-P, where the maximum stress experienced was in the range of $100.051 \mathrm{MPa}$ occurring in the top peripheral regions. On the other hand, the top central region recorded lower stress values of 68.785 $\mathrm{MPa}$. The lowest recorded stress values were in the lower central regions of $6.253 \mathrm{MPa}$. Whereas the lower peripheral regions experienced stresses in the range of 18.76 MPa in the transverse top section as shown in Fig. 2c. As shown in Fig. 2e, straining via 1-P showed a homogenous distribution of the imposed stress along the transverse section of $31.266 \mathrm{MPa}$ in the middle portion of the ECAPed ZK 60 alloy.

It is worth mentioning here that, as ECAP straining continues for multiple passes, more strain was induced.
Accordingly, increasing the straining up to $2-\mathrm{Bc}$ resulted in increasing the maximum stress up to $99.688 \mathrm{MPa}$ recorded in the peripheral regions, whereas the top central regions recorded $68.936 \mathrm{MPa}$ as shown in Fig. $2 \mathrm{~b}, 2 \mathrm{~d}$. The transverse plot showed more homogeneity in stress distribution compared to its 1-P counterpart, which recorded a maximum stress of $44.335 \mathrm{MPa}$ as shown in Fig. 2f. Additionally, from Fig. 3 it is clear that processing via 1-P experienced a maximum effective strain of 1.8 on the top peripheral regions. Whereas the top central regions showed an effective strain of 0.542. Similar to the stress distribution plots, the lower portion of the sample showed a lower effective strain of 0.338 as shown in Fig. 3c. Similar behavior was observed in the strain distribution across the transverse section where the effective strain ranged between 1.875 in the peripheral regions to 0.625 in the central regions as shown in Fig. 3e.

Increasing the straining via ECAP up to 2-Bc resulted in increasing the effective strain up to 2.75 recorded in the top peripheral regions on the longitudinal section, whereas the central regions revealed 1.25 as shown in Fig. 3b, 3d. The same strain values were recorded in the transverse section where the effective strains ranged between 2.75 in the peripheral regions to 1.25 in the central regions as shown in Fig. 3f. Additionally, Fig. 4 shows the processing force versus time for the ZK 60 alloy processed through 1-P and 2-Bc. As shown in Fig. 4 the maximum required force to process the $\mathrm{ZK} 60$ through 1-P is $16 \mathrm{kN}$. Increasing the straining up to $2-\mathrm{Bc}$ resulted in decreasing the maximum processing force to $13 \mathrm{kN}$ which can be attributed to strain softening due to the dynamic recovery resulting from multiple passes.

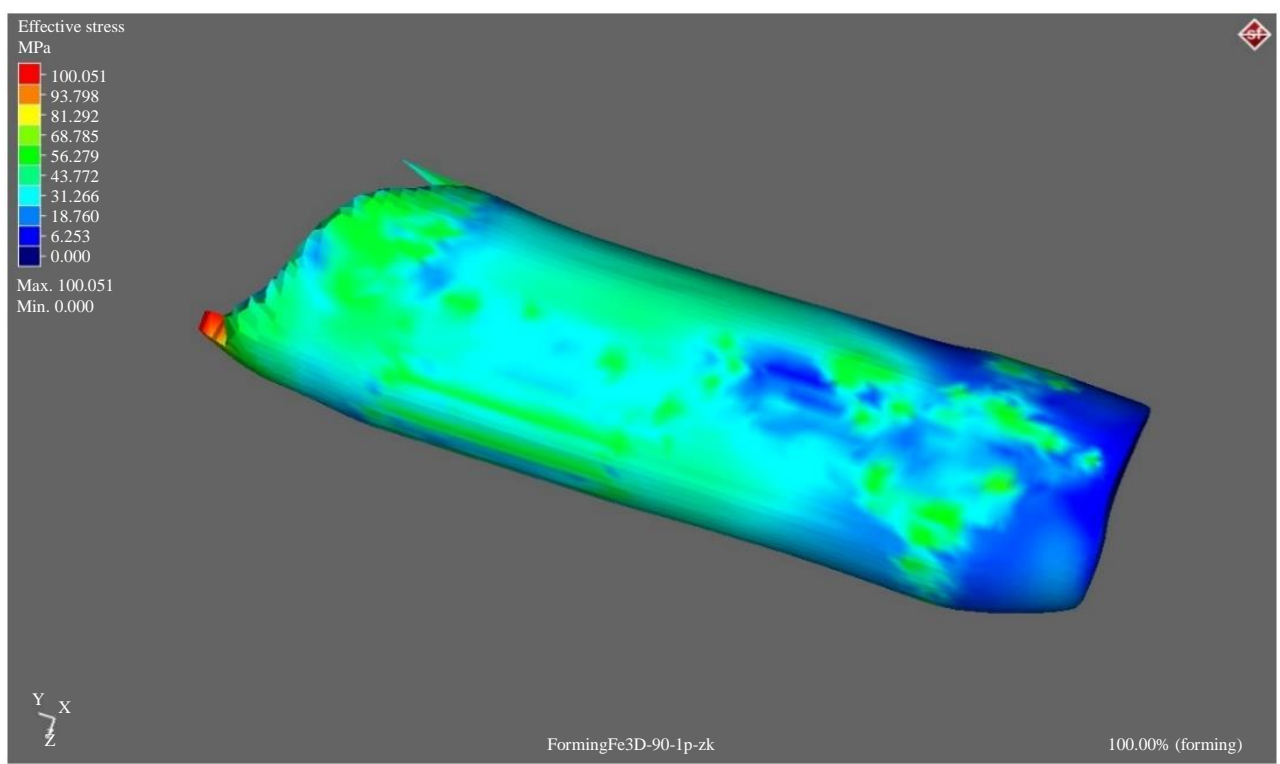

(a) 
Omar Almenaif et al. / American Journal of Engineering and Applied Sciences 2020, 13 (2): 296.310 DOI: 10.3844/ajeassp.2020.296.310

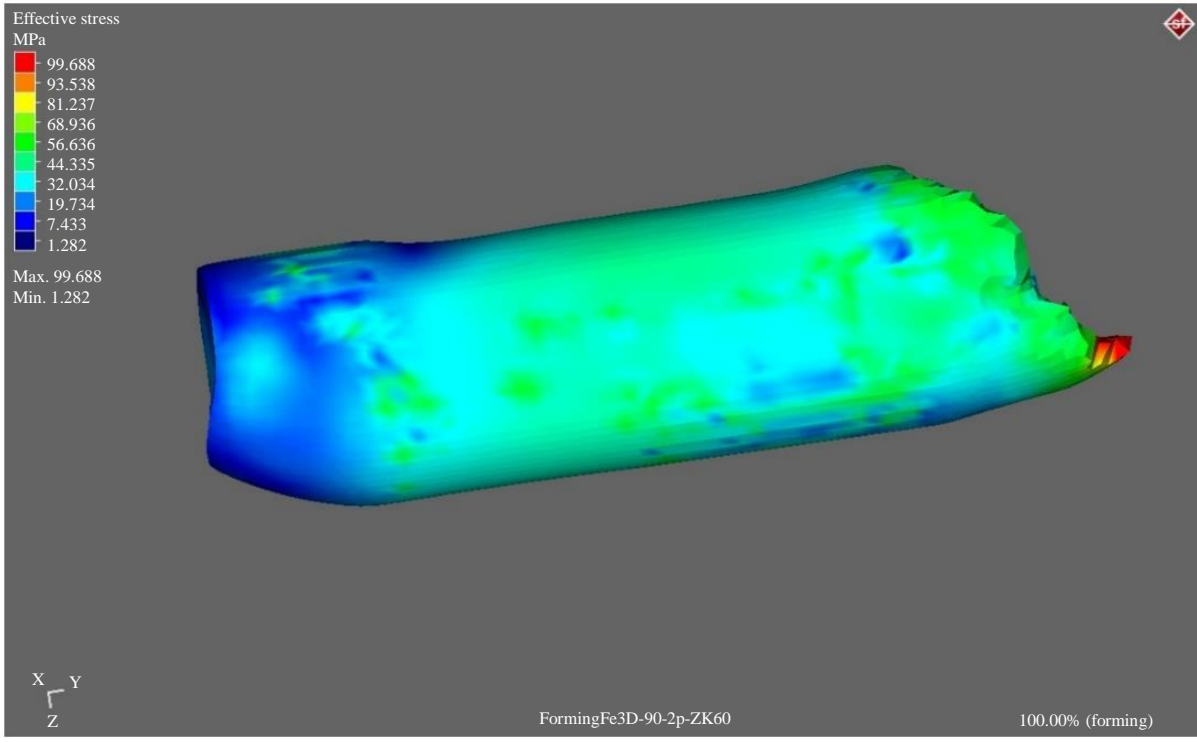

(b)

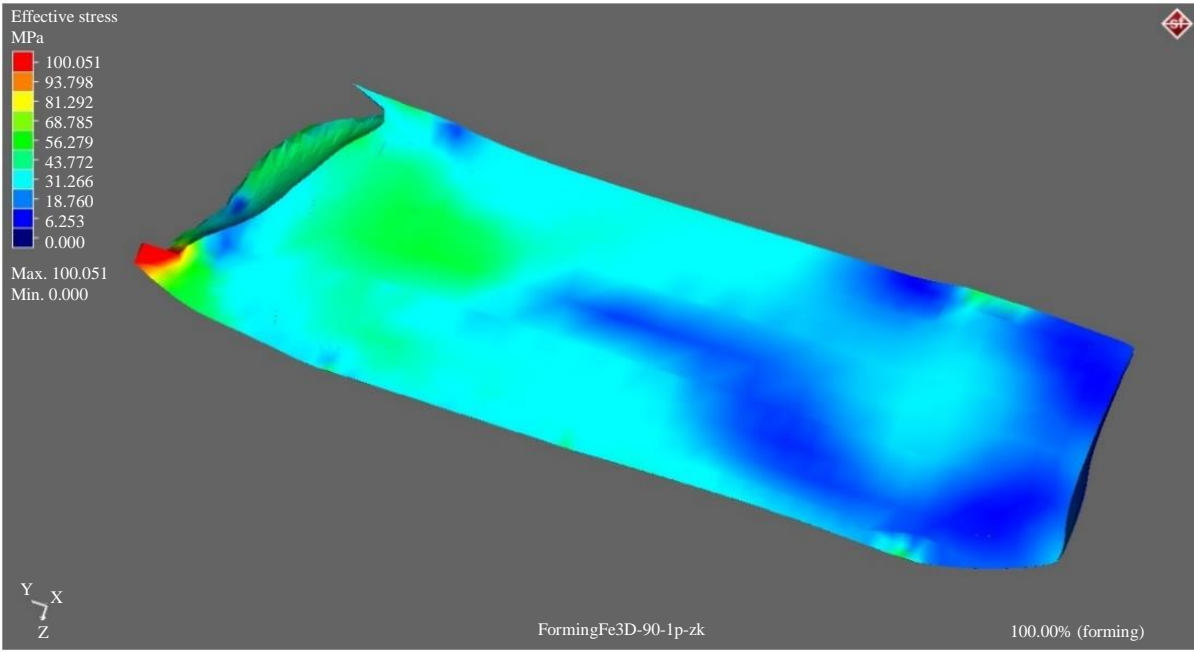

(c)

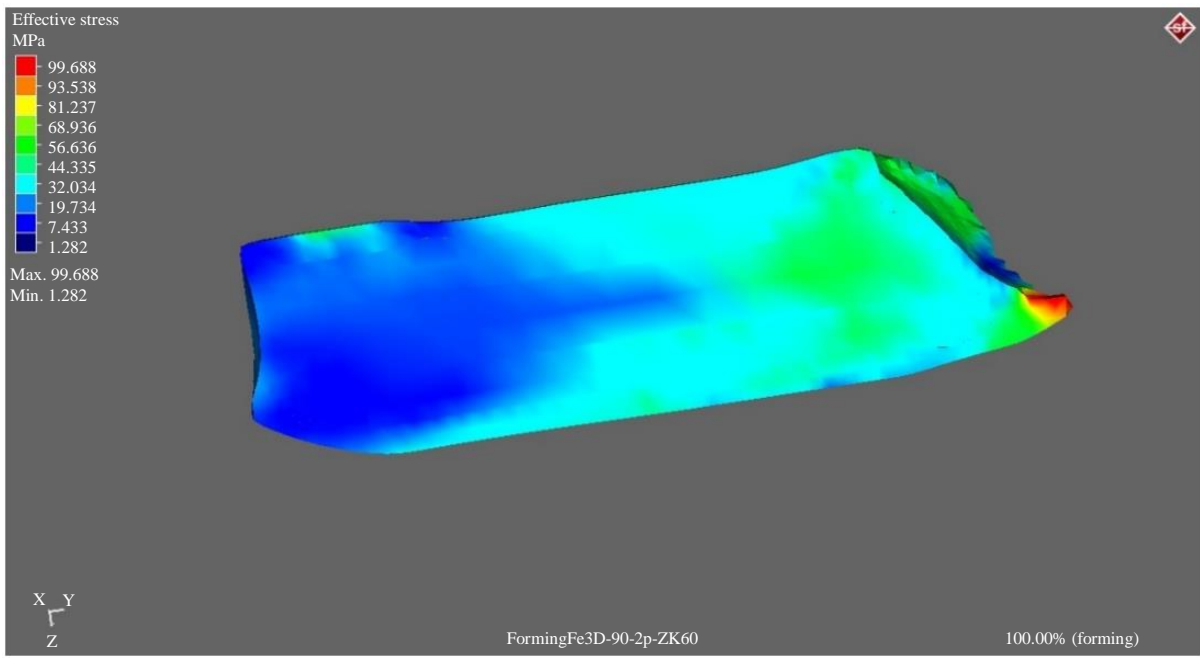

(d) 


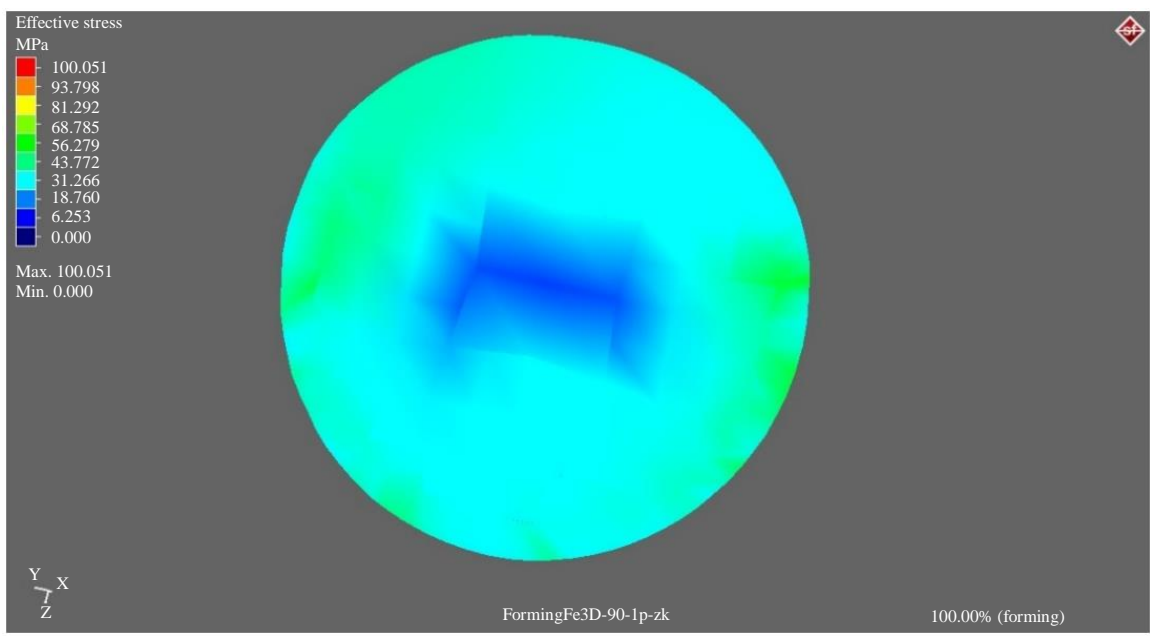

(e)

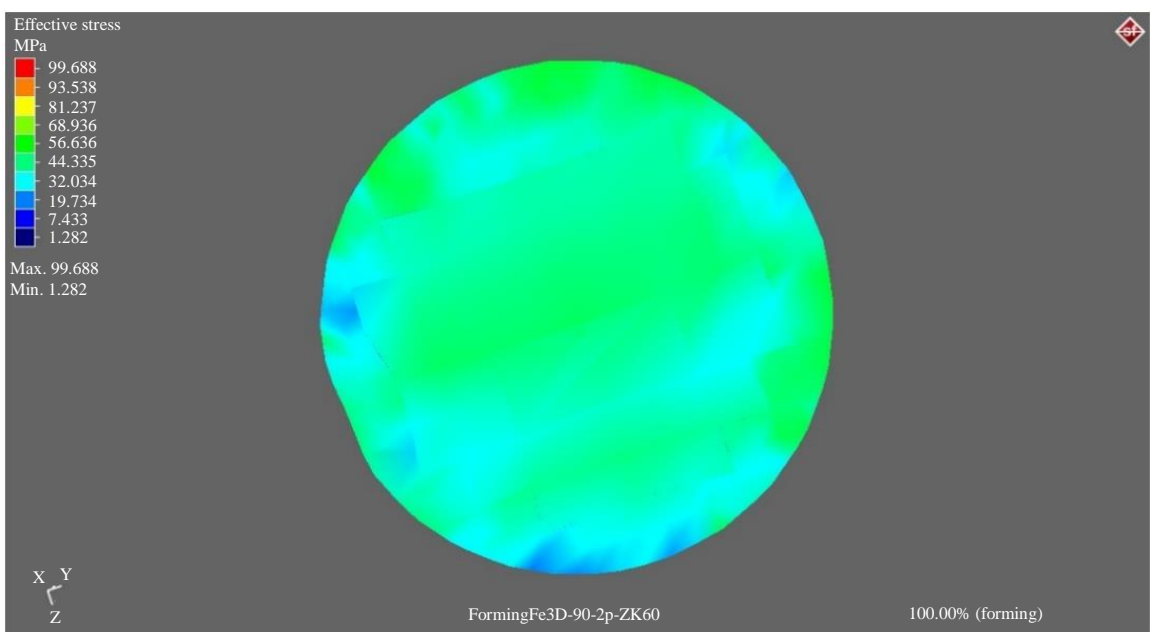

(f)

Fig. 2: Stress distribution in ECAPed ZK 60 samples (a, b), longitudinal sectional view of the stress distribution (c, d), transverse sectional view of the stress distribution (e, f) processed through 1-P (a, c, e) and 2-Bc (b. d, f)

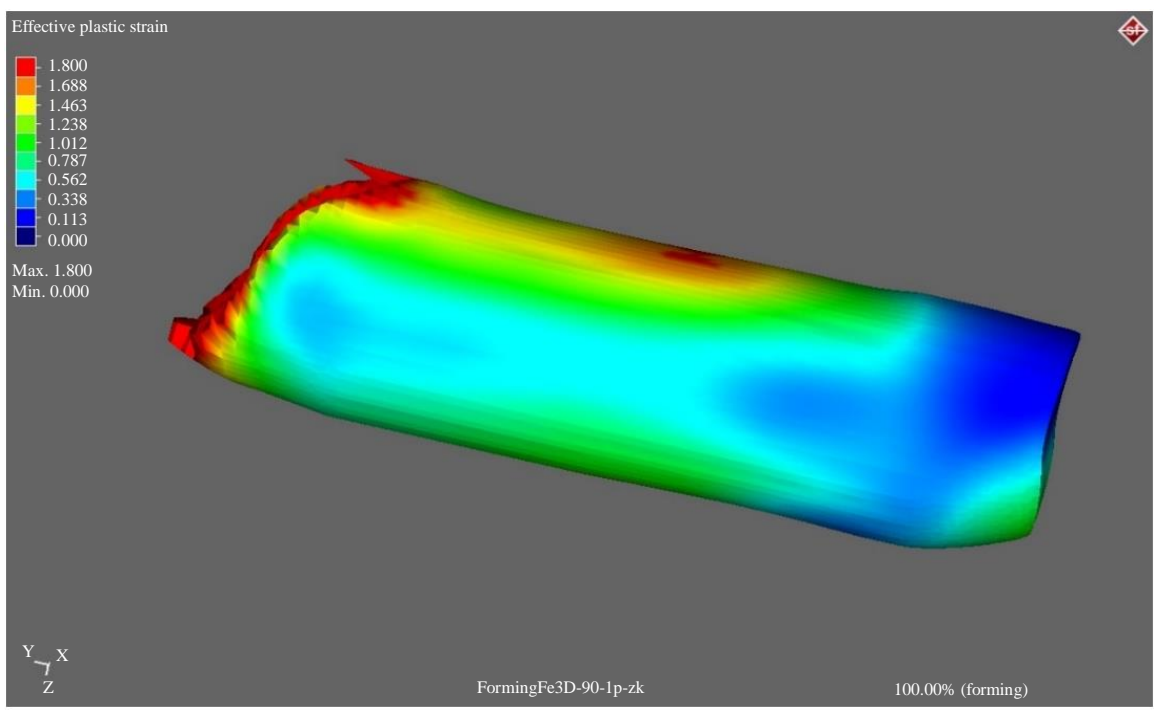

(a) 
Omar Almenaif et al. / American Journal of Engineering and Applied Sciences 2020, 13 (2): 296.310 DOI: 10.3844/ajeassp.2020.296.310

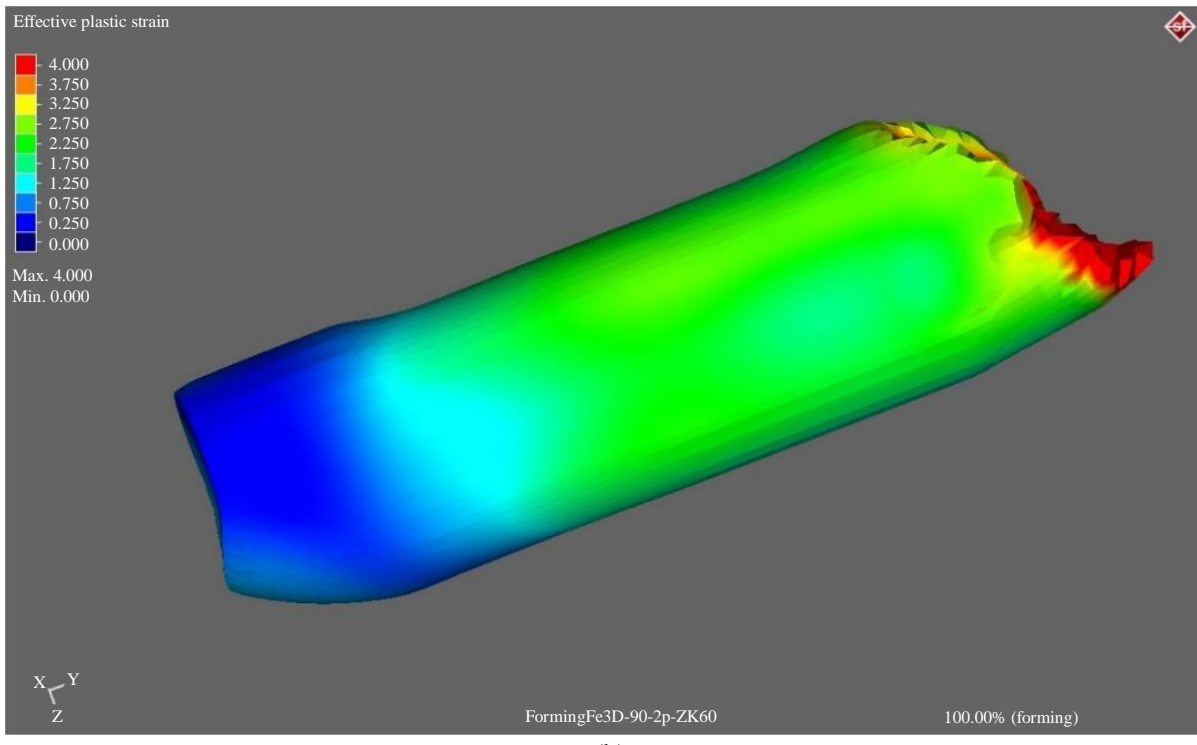

(b)

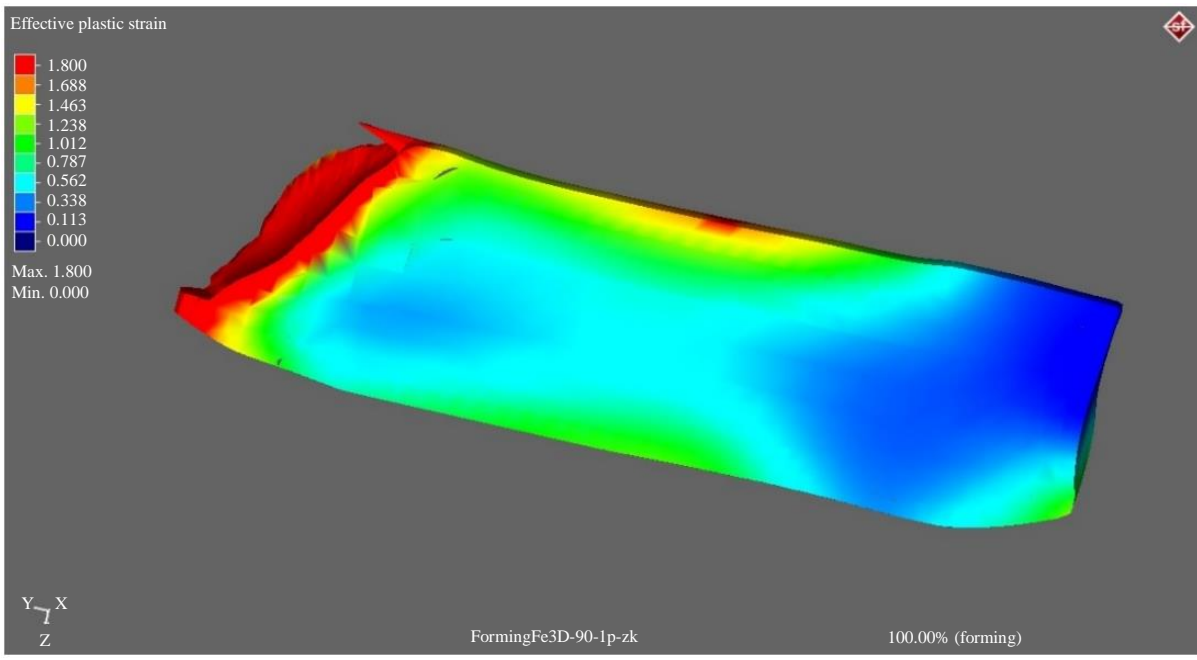

(c)

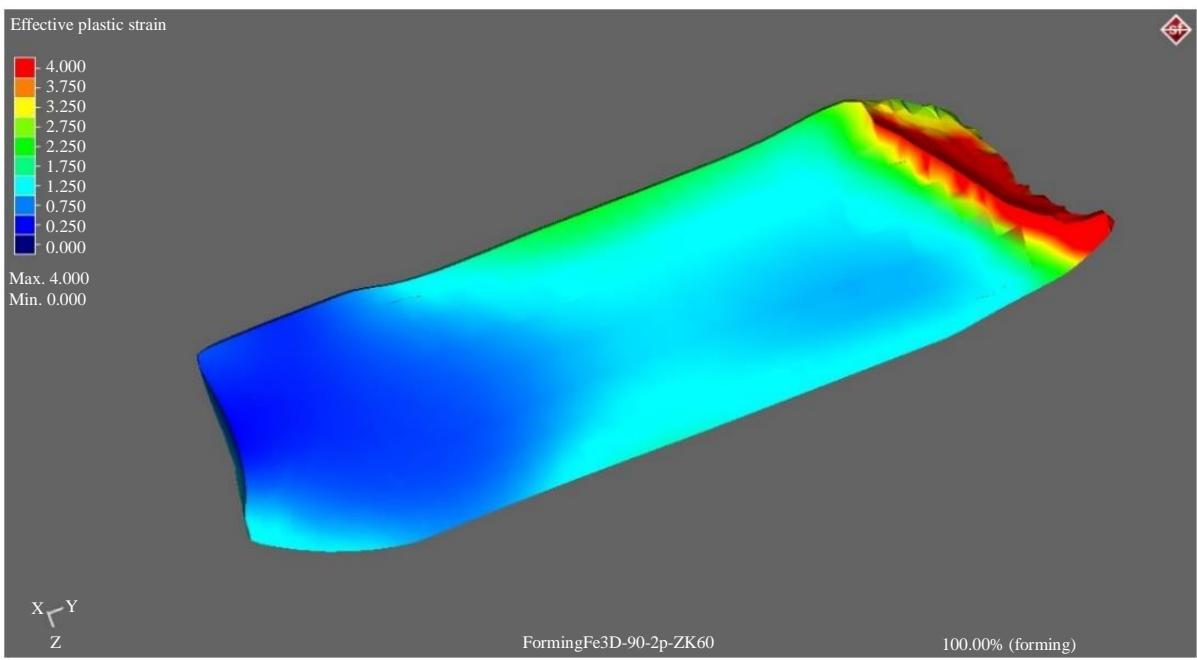

(d) 


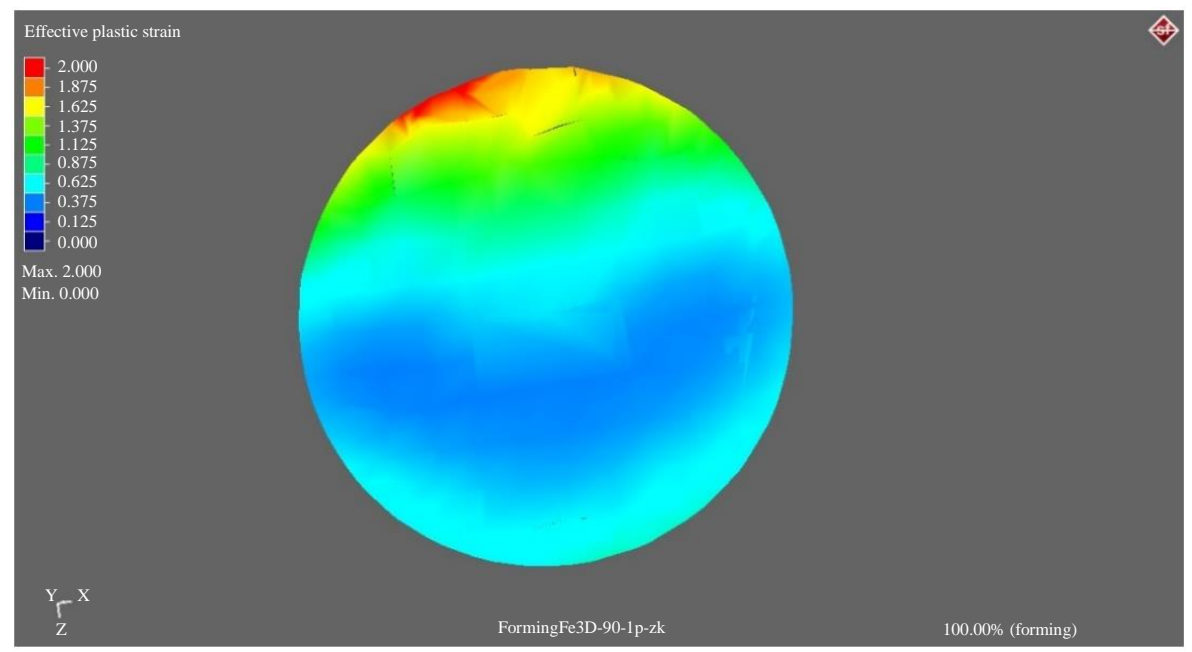

(e)

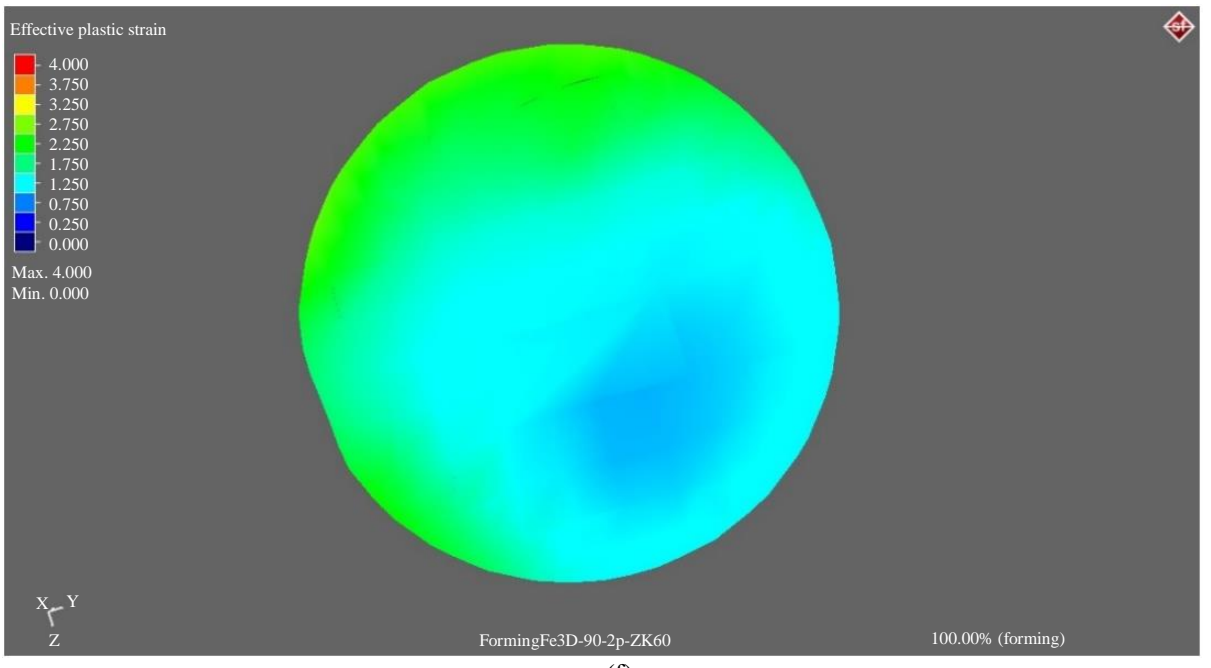

(f)

Fig. 3: Effective strain distribution in ECAPed ZK 60 samples $(a, b)$, longitudinal sectional view of the strain distribution (c, d), transverse sectional view of the strain distribution (e, f) processed through 1-P (a, c, e) and 2-Bc (b. d, f)

Table 1: Average Values of (Hv) measured at centre and peripheries

\begin{tabular}{llll}
\hline & Vickers micro-hardness average values (Hv) \\
& As-annealed & $1-\mathrm{P}$ & 2-Bc \\
\hline Centre & 55 & 75 & 87 \\
Near peripheries & & 101 & 124 \\
\hline
\end{tabular}

Furthermore, Fig. 5 shows the relation between the stress and time at the peripheries and center of the ZK 60 billets processed through 1-P and 2-Bc. Similarly, the strain comparison is shown in Fig. 6. As shown in Fig. 5, the maximum average stress in the 1-P condition was 60 and 59 $\mathrm{MPa}$, at the peripheries and center of the sample, respectively. On the other hand, the maximum average stress in the 2-Bc condition was 58 and $52 \mathrm{MPa}$, at the peripheries and center of the sample, respectively, which is agrees with the relation between the processing force and time shown in Fig. 4. In addition, the effective average strain imposed on the ZK 60 billets processed through 1-P was 1.15 and 0.61 at the sample's periphery and center, respectively as shown in Fig. 6. Increasing the straining via ECAP by increasing the number of passes up to 2-Bc resulted in increasing the effective strain to 2.3 and 1.2 at the sample's peripheries and center, respectively.

\section{Hardness Variation}

Shown in Table 1 is the average Vickers microHardness values (Hv) of the as-annealed ZK60 billets at the peripheral and central areas alongside after ECAP processing via 1 and $2-\mathrm{Bc}$. The as-annealed billet has homogenously distributed hardness with an average hardness reading of $55 \mathrm{Hv}$. From Table 1, it is clear that the $\mathrm{Hv}$ values increased with increasing the number of ECAP passes, which occurred as a result of strain hardening which caused the predominant effect of increasing dislocation density. 
Omar Almenaif et al. / American Journal of Engineering and Applied Sciences 2020, 13 (2): 296.310 DOI: 10.3844/ajeassp.2020.296.310

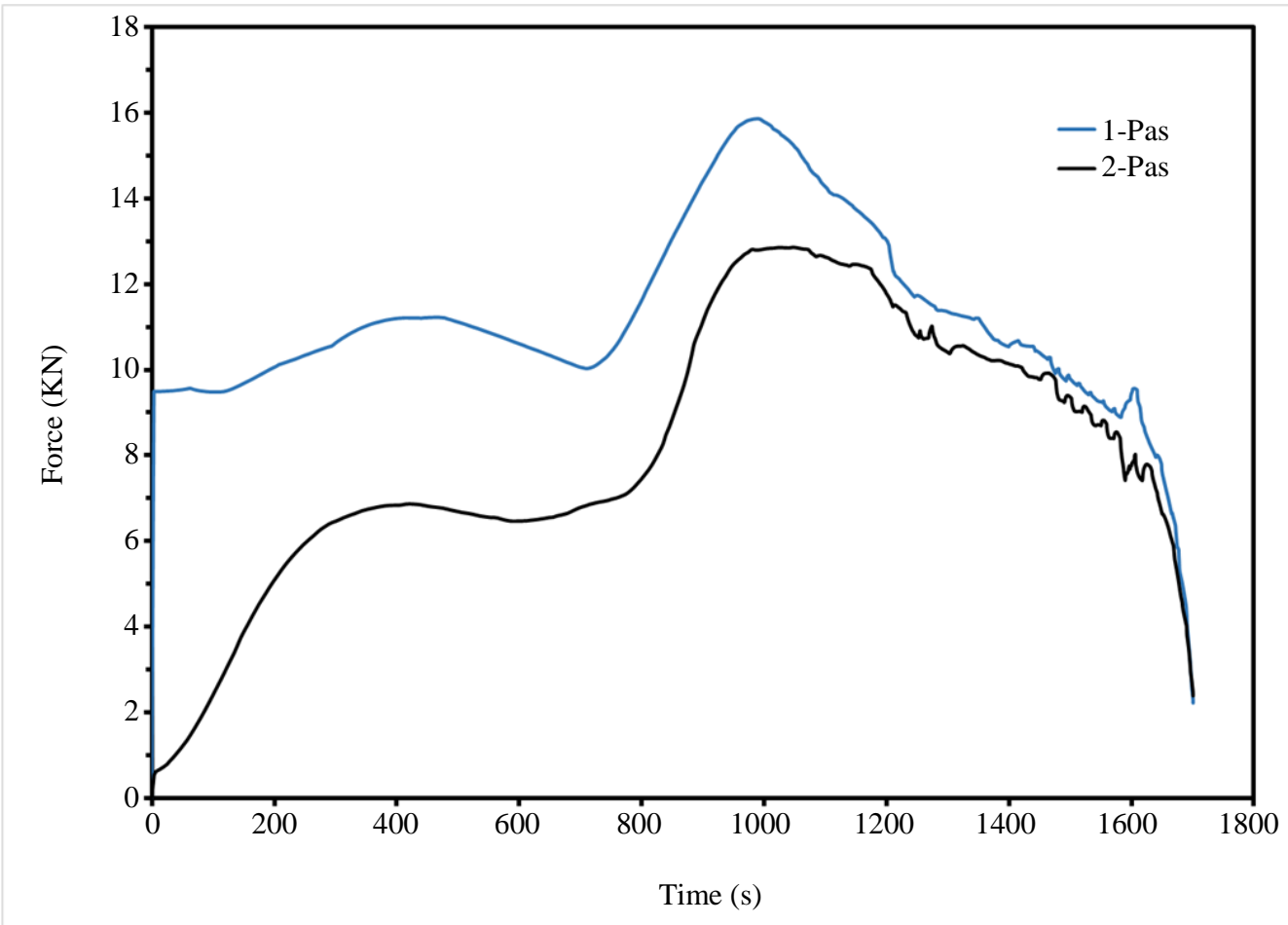

Fig. 4: The ECAP force versus time during processing through1-P and 2-Bc

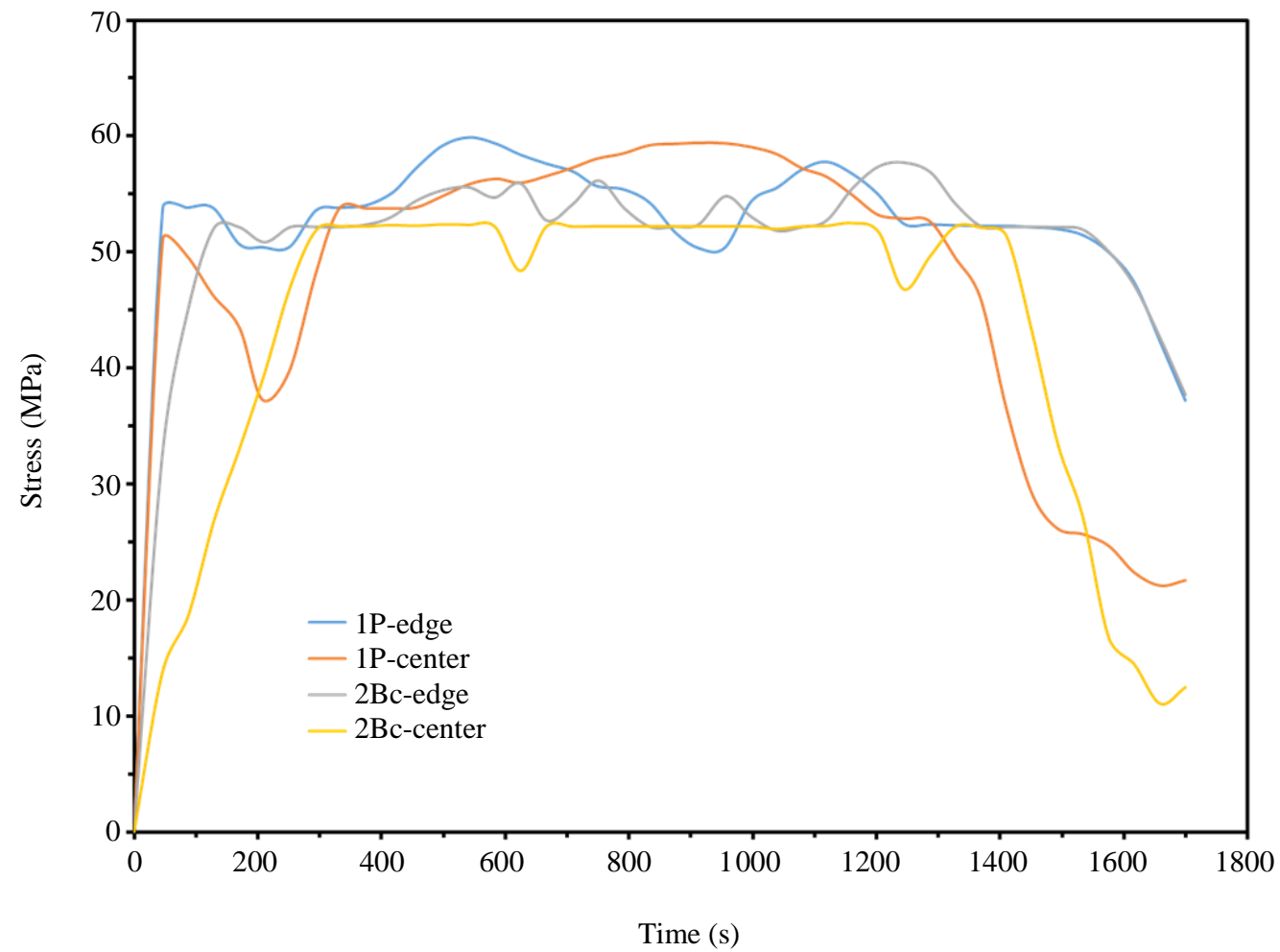

Fig. 5: The ECAP stress versus time during processing through1-P and 2-Bc at the sample peripheral and central regions 


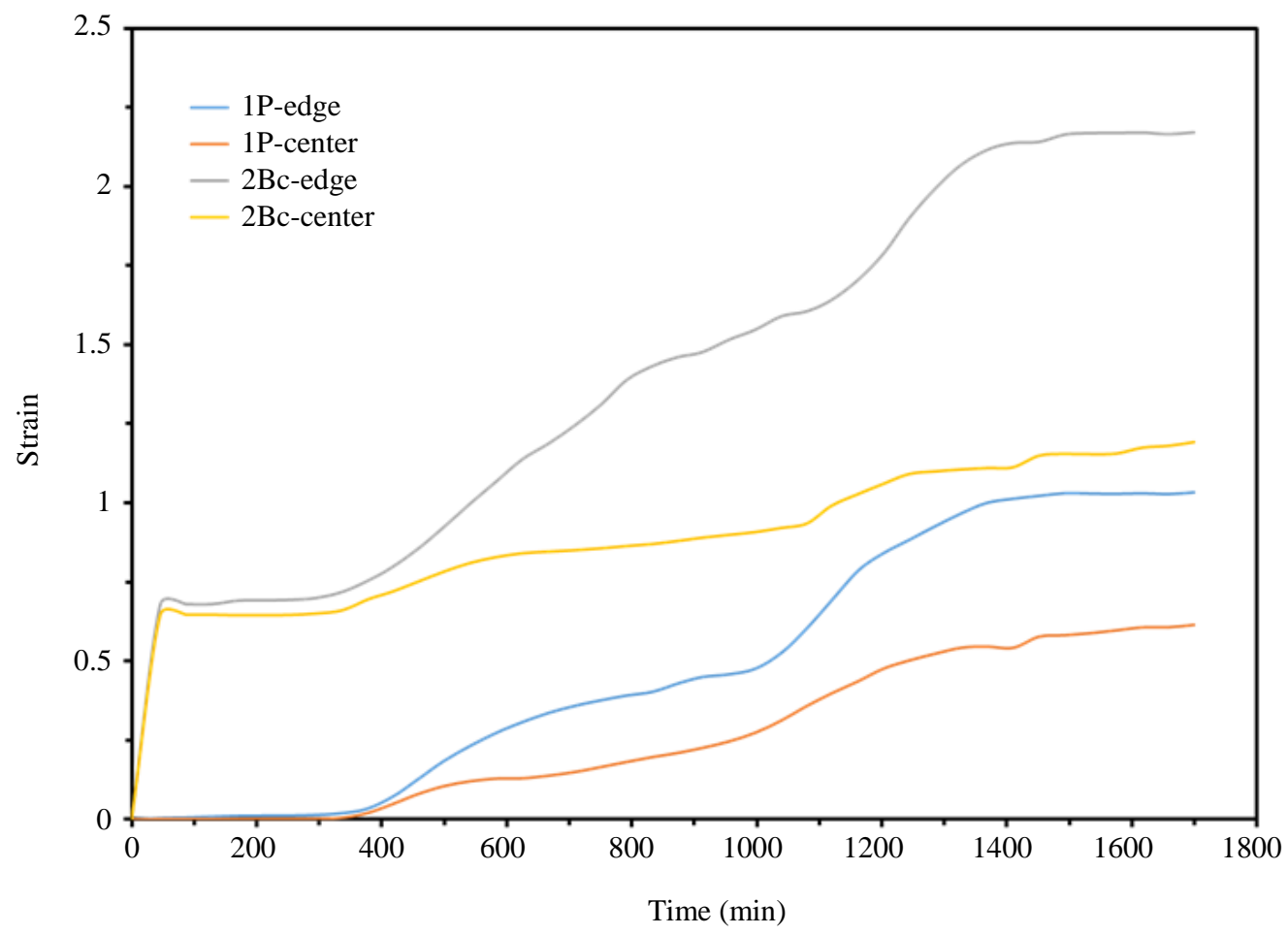

Fig. 6: The ECAP effective strain versus time during processing through1-P and 2-Bc at the sample peripheral and central regions

1-P processing via ECAP yielded a $36.4 \%$ increase in the Vickers micro-hardness (Hv) values of the billet's central area, while processing up to 2-passes via Bc (2$\mathrm{Bc})$ resulted in a notable increase of $58 \%$ in $(\mathrm{Hv})$ values when put in comparison with the $\mathrm{Hv}$ of the as-annealed samples. In addition, the peripheral regions of thw billets' ECAPed via 1-P and 2-Bc passes, respectively, displayed 83.6 and $125.4 \%$ increases in $\mathrm{Hv}$ value, when put in comparison with the as-annealed samples. Accordingly, the $\mathrm{Hv}$ values that were found at the peripheral regions surpassed that of the central regions, this could be linked to the high friction induced at the die-billet's interface, which resulted in the increased strain hardening effect at the peripheries, which caused it to surpass that of the center. These findings are consistent with Balogh et al. (2010), they reported in previous work that the micro-hardness values in the $\mathrm{ZK}$ 60 alloy displayed a small increase between the 1 and the 4 passes threshold and then slightly decreased after being processed by eight ECAP passes (route $\mathrm{Bc}$ ) through a $90^{\circ}$ die-set at $200^{\circ} \mathrm{C}$.

In addition, a hardness contour map displaying the hardness distribution along the transverse cross section of the ECAPed billets versus distance measured from the billets' centre to periphery regions is shown in Fig. 7a. From Fig. 7a and 7b, it can be revealed that there is a significant increase in the $\mathrm{Hv}$ after the first pass and then a slow increase with the increase of the number of passes. From Fig. 7a- up to- Fig. 7b, the hardness contour maps revealed that $\mathrm{Hv}$-values become more uniform when the number of passes is increased from 1 to $2-\mathrm{Bc}$, respectively. From Fig. 7, it is clear that, the lowest hardness values were noticed at the central region of the ECAPed sample, then the $\mathrm{Hv}$ values increase radially.

As shown in Fig. 7, processing via 1-P revealed $34.4 \%$ and $83.6 \%$ increases in the $\mathrm{Hv}$ values at the central and peripheral regions, respectively, when put in comparison with to the as-annealed condition. This invariably implies that the distribution of $\mathrm{Hv}$-values is largely inhomogeneous across the billet's transverse section. (Fig. 7a). However, the homogeneity of the hardness distribution of the billets across their transverse section is directly proportional with the number of passes as shown in Fig. 7b. ECAP via the 2-Bc route correlated with rises in $\mathrm{Hv}$ values across the center and peripheries by $58 \%$ and $125.4 \%$ s respectively, when compared with the as-annealed conditions. This indicates a rise in the uniformity of the deformation across the billets' cross section as the number of passes increased. This discovered surge in hardness at the peripheral regions in comparison with the center is due to the friction between the billet's and ECAP die's walls. Accordingly, this agree with the simulation plots for the effective stress and strain imposed to the ECAPed samples as shown in Figs. 2 and 3. 


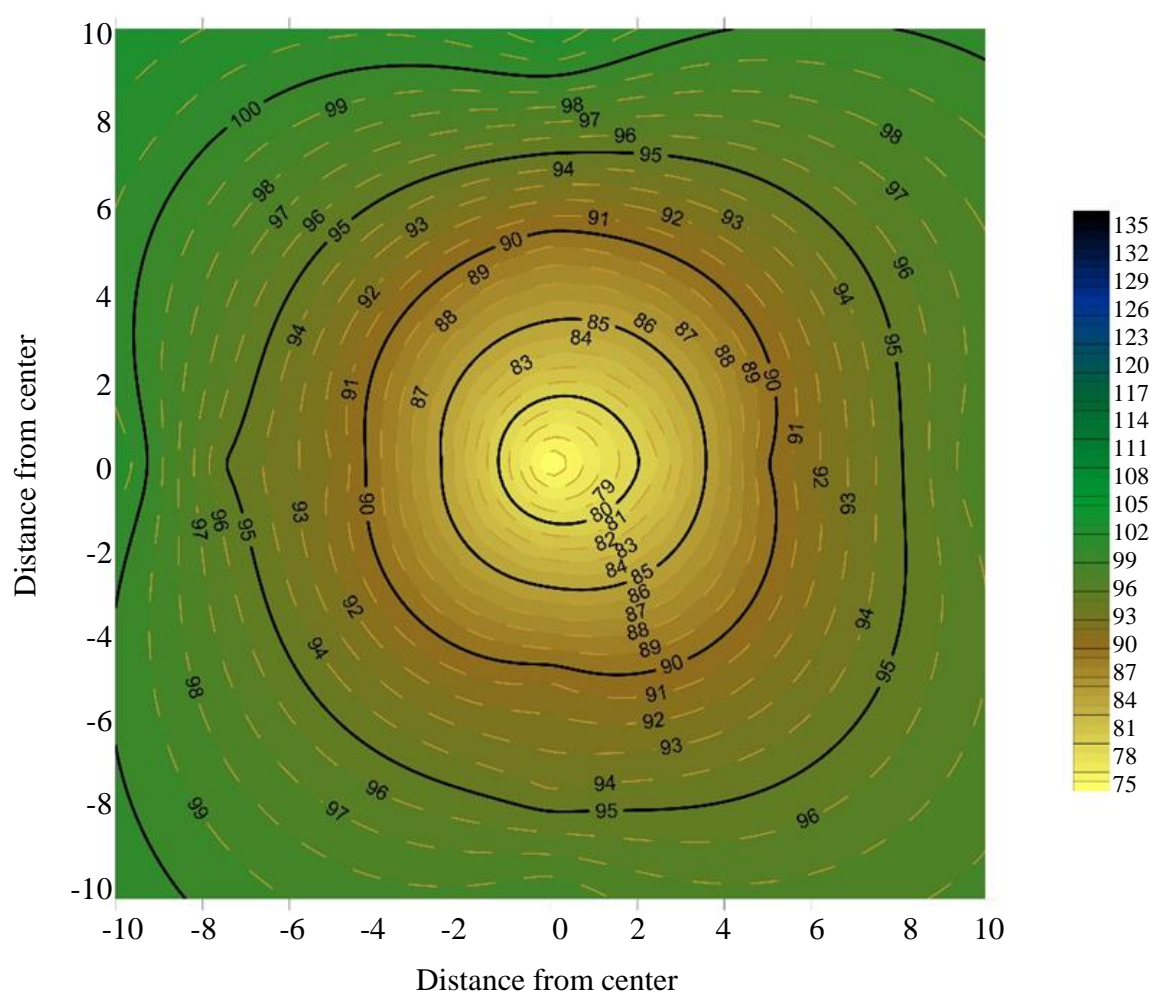

(a)

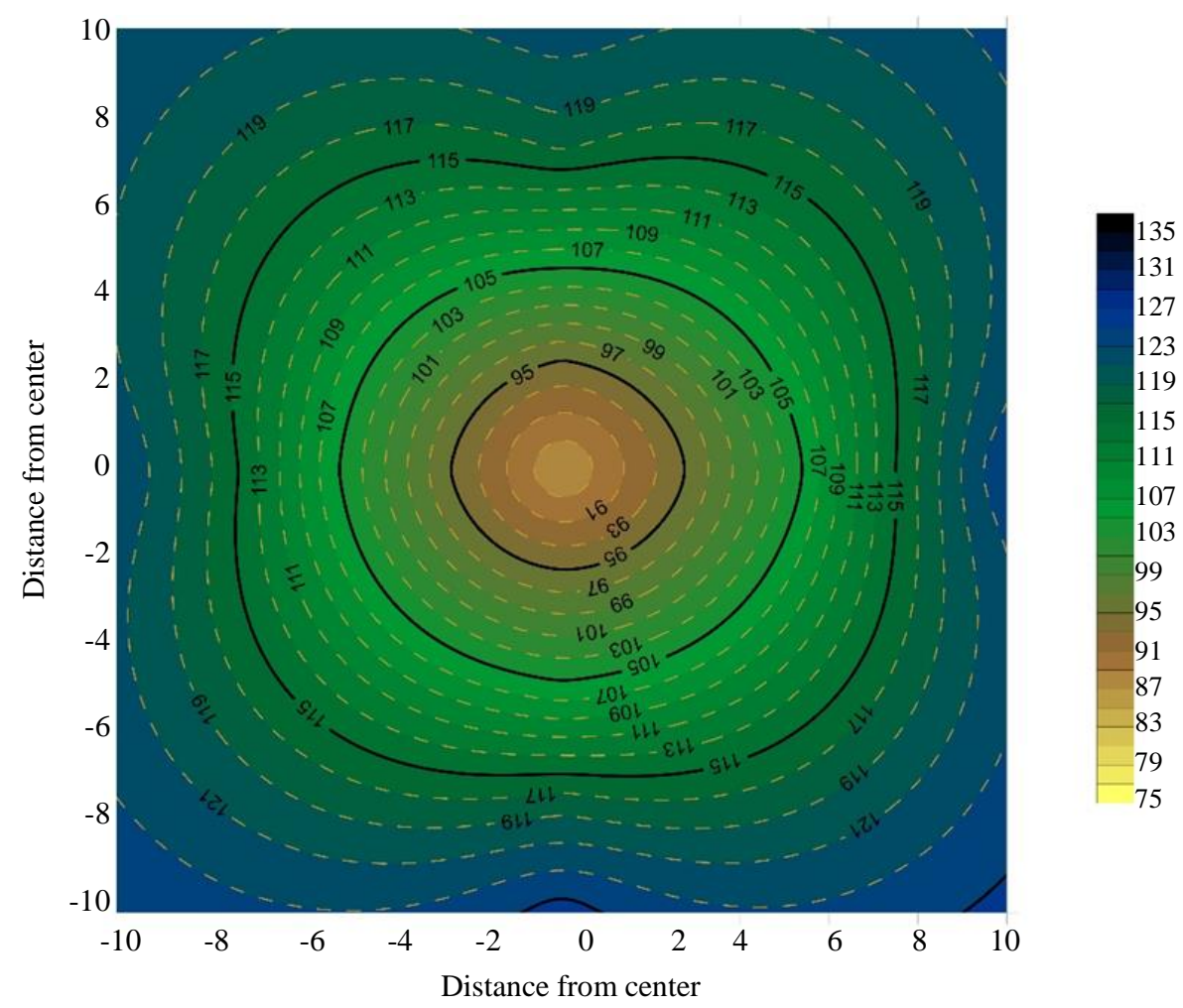

(b)

Fig. 7: Color-coded contour for the Hv- values recorded on the top transverse cross section of the ECAPed processed billets through: (a) 1-P and (b) 2-B 
Accordingly, ECAP processing is usually accompanied with production, multiplication and locking of dislocations processes which results in formation of Low Angle Grain Boundaries (LAGBs) and High Angle Boundaries (HAGBs) and finally, formation of UFG materials (Kyungjin Kim and Yoon, 2010; Segal, 2018), which inhibit dislocationglide thus leading to strengthening the material (Martynenkoa et al., 2018). This increase in strength and in hardness in the ECAPed billets could be ascribed to the homogeneous refined structure developed during the process. The increase in both hardness and strength of the ZK 60 billets can be explained by the substantial grain refinement resulting from the fact that SPD follows the Hall-Petch equation (Suresh et al., 2019). Accordingly, there is a directly proportional relation between finer grain sizes and the area of grain boundaries, where finer grain sizes produce a higher surface area of grain boundaries to obstruct the motion of dislocations. Consequently, developments may occur in the ultrafine substructure within the sheared grains of the as-annealed sample, which may occur as dislocation cells or subgrains depending on the misorientation angles.

Furthermore, in all SPD techniques the hardness and strength are significantly impacted by strain hardness, where strain hardness aids in their enhancement. The formation and multiplying in the number of HAGBs due to the rise of shear strain can be attributed to two reasons: (1) New HAGBs are formed by grain subdivision processes and (2) after the new HAGB molecules are formed, both the pre-existing Grain Boundaries (HAGBs) and new ones undergo an extension process to an extent proportional to strain (Suresh et al., 2019). Meanwhile, dynamic recovery occurred normally, with the only difference is that multiplication of dislocations in the sample occurred at a faster rate than those conventionally countered by dynamic recovery. This net increase in dislocations formed an excess of them within grains and near grain or sub grain boundaries which furthermore made dislocation glide more difficult. Thus, the dislocation density in the deformed samples increased with as we did more ECAP passes, both due to dislocation multiplication or the formation of new dislocations. The conclusive result afterwards was that the motion of a dislocation was hindered by the presence of other dislocations due to reasons explained above, which agreed with the discovered significant increase of hardness after ECAP processing (Huang et al., 2020; Elhefnawey et al., 2020; Ma et al., 2019; Yuan et al., 2019; Yang et al., 2019).

\section{Compressive Properties}

To analyze and establish the mechanical properties of the materials under compression loads, a compression test is conducted. This test is done by applying the compression loading to a cylindrical sample which has a low height to diameter ratio. Unlike in tension tests where the maximum stress is reached when the necking becomes significant just before the sample is torn, the max compression is reached when the cracking of the compression sample is reached.

Table 2 lists the changes in the Ultimate Compressive Strength (UCS) and fracture strain $\left(\varepsilon_{f}\right)$ of the ECAPed samples side-by-side to the as-annealed one. Moreover, Fig. 8 shows the UCS and $\varepsilon_{f}$ variation as a function of ECAP passes compared to the asannealed billets. As shown in Fig. 8, a significant improvement in the ultimate compressive strengths were observed after processing via 1-pass coupled with a decrease in the ductility. The stress-strain curves showed that using ECAP to impose intense SPD produced a work-hardened material with improved yield and ultimate compressive strengths. These improvements are a result of the multiplication of dislocations and their interaction together. As shown, a trend was discovered where compressive properties increase with increasing the number of passes.

The highest ultimate stress was that of the sample 2$B_{c}$ while the 1-P sample had a close value. Slight oscillations of the curves (just before reaching the ultimate compression stress) are visible near the end. The segments of the curves between the yield and ultimate points is almost linear for all the samples which reveals the ductile properties of the material.

From Fig. 8 and Table 2, it becomes apparent that the UCS showed an increase of $39.8 \%$ coupled with a decrease in the fracture strain by $11 \%$ after processing through 1-P when compared to the as-annealed samples. Cumulative straining up to $2-\mathrm{Bc}$ revealed additional increasing of the UCS by $10 \%$ coupled with additional decrease of the fracture strain by $12.5 \%$ compared to the 1-P counterpart. This increase in UCS coupled with the extra number of passes affected both the uniform and non-uniform strain when put in comparison with the as-annealed samples. Such an impact is ascribed to the accretion of strain following each pass, resulting in the increased UCS percentages due to strain hardening.

Table 2: The compressive properties for the ECAP processed samples compared with the as-annealed condition

\begin{tabular}{lll}
\hline No. of pass & $\sigma_{u}(\mathrm{MPa})$ & $\varepsilon_{f}$ \\
\hline As received & 221 & 27 \\
$1-P$ & 309 & 24 \\
$2-B_{c}$ & 340 & 22 \\
\hline
\end{tabular}




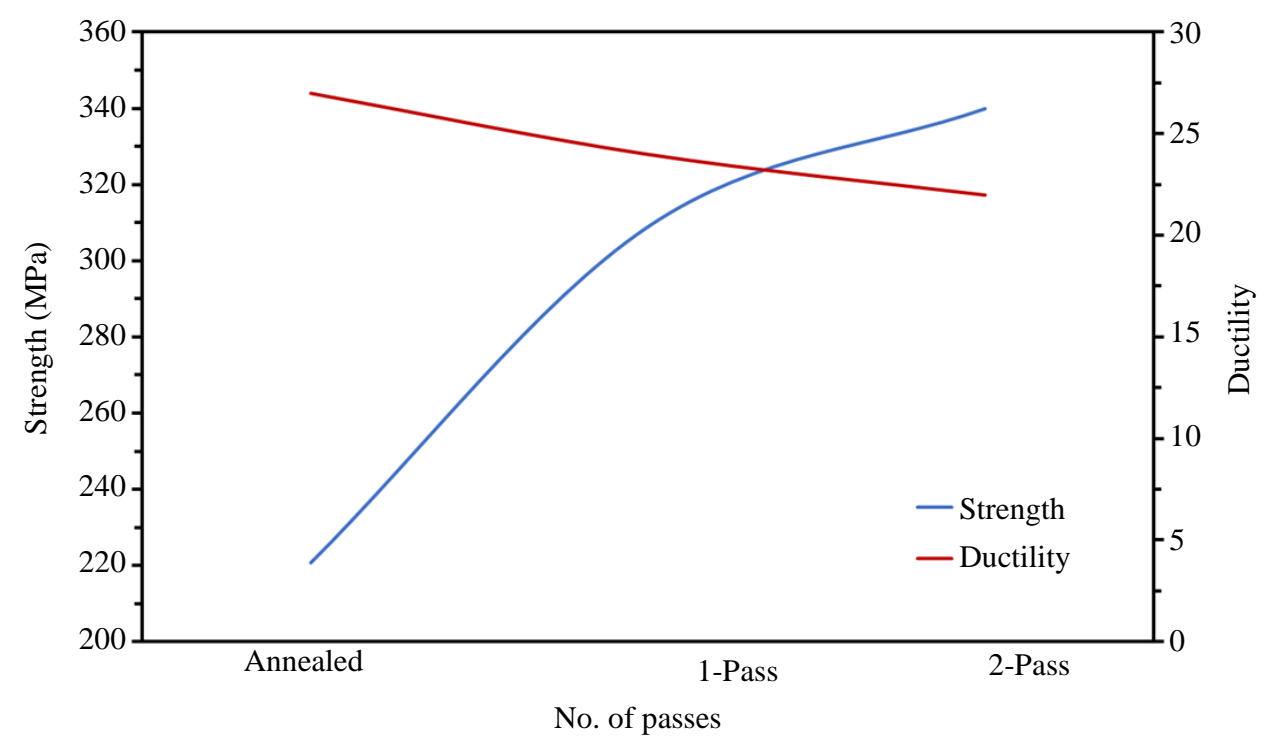

Fig. 8: Graph showing the compressive properties variation as a function of increasing ECAP passes of ZK 60 alloy

The present investigation confirmed the potential for achieving UFG structure on the Nano-scale level, hence producing high UCS ZK 60 alloy billets processed through ECAP. This significant increase in the alloy's strength after ECAP processing is caused by the newly obtained homogeneous UFG microstructure which constituted a significant strengthening element according to the Hall-Petch equation (Balogh et al., 2010; Kyungjin Kim and Yoon, 2010; Dumitru et al., 2014; Sabbaghianrad et al., 2018). The rate of strength increase of the ECAP processed billets increased by increasing the amount of shear strain as displayed in Fig. 3. This can be attributed to the UFG evaluated via ECAP processing. The higher the amount of shear strain, the more the refinement of the structure. In addition, the increment of the precipitation of intermetallic phases in the matrix of the material leads to increasing the strength of the processed ZK 60 alloy (Dumitru et al., 2014).

It is worth mentioning here that, the compression tests of ZK 60 alloy, heated up to $200-250^{\circ} \mathrm{C}$ were followed by continuous dynamic recrystallization which are associated with dislocation slips (Galiyev et al., 2001). During ECAP, dislocation motion was obstructed by the grain boundaries which led to entanglement of the dislocation network. The entangled dislocations can be easily rearranged into dislocation and sub-grain boundaries (Kuhlmann-Wilsdorf, 1996). Further operation of the ECAP process would cause the dislocation spawning continue generating dislocations in the sub-grain interior. The dislocations move across the sub-grains and are absorbed by the sub-grain boundaries, causing them to be more mis-oriented. Consequently, the LAGBs persistently evolved into HAGBs, which is a considered a continuous dynamic recovery and recrystallization process of sorts. The slip dislocations were mostly consumed in the transformation from LAGBs to HAGBs. Therefore, we can conclude that further straining is more effective in increasing the misorientation of the grain boundaries. However, the grain refinement is not as effective, compared with other methods (Hea et al., 2010) and hence, processing through $2-\mathrm{Bc}$ revealed less improvement in the mechanical properties than 1-P processing.

\section{Conclusion}

In this study, the effect of Equal Channel Angular Processing (ECAP) on the mechanical characterization of ZK 60 alloy was investigated. In addition, this was study undertaken to validate the deformation capabilities of ECAP through a combination of numerical and experimental analysis. The effective stress and strain induced as a result of ECAP deformation, the evolution of the hardness distribution and the compressive properties of biodegradable magnesium alloy are outlined. The following results summarize the most significant achievements of this work:

1. The FE analysis revealed that the maximum stresses were displayed at the corner and peripheral areas compared to the central areas

2. Straining through 1-P resulted in increasing the maximum stress up to $100.051 \mathrm{MPa}$, recorded in the peripheral regions

3. Processing via 1-P yielded a maximum effective strain of 1.8 in the top peripheral regions, whereas the top central regions showed an effective strain of 0.542

4. Increasing the straining up to $2-\mathrm{Bc}$ resulted in increasing the effective strain up to 2.75 , recorded in the top peripheral regions. Whereas the central regions experienced an effective strain of 1.25 
5. ECAP processing via 2-Bc correlated with rises in $\mathrm{Hv}$ values across the center and peripheries by $58 \%$ and $125.4 \%$ respectively, when compared with the as-annealed conditions

6. Cumulative straining up to $2-\mathrm{Bc}$ revealed an increase of the UCS by $53.8 \%$ coupled with a decrease in the fracture strain by $18.5 \%$ compared with the as-annealed counterpart

\section{Acknowledgment}

The authors would like to acknowledge the support extended by the Mechanical Engineering department, College of Engineering- Unaizah, Qassim University by way of facilitating the use of the processing and testing equipment. Gratitude is also expressed to the Fresh Factory for Tools and Dies for their appreciable effort in manufacturing the ECAP die.

\section{Author's Contributions}

All authors equally contributed in this work.

\section{Ethics}

This article is original and contains unpublished material. Authors declare that are not ethical issues and no conflict of interest that may arise after the publication of this manuscript.

\section{References}

Alvarez-Lopez, M., 2010. Corrosion behaviour of AZ 31 magnesium alloy with different grain sizes in simulated biological fluids. Acta Biomater., 6: 1763-1771. DOI: 10.1016/j.actbio.2009.04.041

Aung, N.N. and W. Zhou, 2010. Effect of grain size and twins on corrosion behaviour of AZ 31 B magnesium alloy. Corros. Sci., 52: 589-594.

DOI: 10.1016/j.corsci.2009.10.018

Balogh, L., R.B. Figueiredo, T. Ungár and T.G. Langdon, 2010. The contributions of grain size, dislocation density and twinning to the strength of a magnesium alloy processed by ECAP. Mater. Sci. Eng. A, 528: 533-538.

DOI: $10.1016 /$ j.msea.2010.09.048

Ding, R., C. Chung, Y. Chiu and P. Lyon, 2010. Effect of ECAP on microstructure and mechanical properties of ZE41 magnesium alloy. Mater. Sci. Eng. A, 527: 3777-3784. DOI: 10.1016/j.msea.2010.02.030

Dumitru, F.D., O.F. Higuera-Cobos and J.M. Cabrera, 2014. ZK 60 alloy processed by ECAP: Microstructural, physical and mechanical characterization. Mater. Sci. Eng. A, 594: 32-39. DOI: 10.1016/j.msea.2013.11.050
El Garaihy, W.H., 2020. Numerical and experimental analyses of equal channel angular processing of pure aluminum. Adv. Mater. Lett., 11: 1-5.

Elhefnawey, M., G.L. Shuai, Z. Li, M. Nemat-Alla and D.T. Zhang et al., 2020. On achieving superior strength for Al-Mg-Zn alloy adopting cold ECAP. Vacuum, 174: 1-9. DOI: 10.1016/j.vacuum.2020.109191

Galiyev, A., R. Kaibyshev and G. Gottstein, 2001. Correlation of plastic deformation and dynamic recrystallization in magnesium alloy ZK60. Acta Mater., 49: 1199-1207. DOI: $10.1016 / \mathrm{S} 1359-6454(01) 00020-9$

Ge, Q., D. Dellasega, A.G. Demir and M. Vedani, 2013. The processing of ultrafine-grained $\mathrm{Mg}$ tubes for biodegradable stents. Acta Biomater., 9: 8604-8610. DOI: 10.1016/j.actbio.2013.01.010

Hea, Y., Q. Pana, Y. Qin, X. Liu and W. Li et al., 2010. Microstructure and mechanical properties of ZK 60 alloy processed by two-step equal channel angular pressing. J. Alloys Compounds, 492: 605-610. DOI: 10.1016/j.jallcom.2009.11.192

Howeyze, M., A.R. Eivani, H. Arabi and H.R. Jafarian, 2018. Effects of deformation routes on the evolution of microstructure, texture and tensile properties of AA5052 aluminum alloy. Mater. Sci. Eng. A, 732: 120-128. DOI: 10.1016/j.msea.2018.06.081

Hu, W.W., Z.Q. Yang and H.Q. Ye, 2017. Dislocations and their interactions with other crystal defects in a Mg alloy. Acta Mater., 124: 372-382. DOI: 10.1016/j.actamat.2016.11.015

Huang, R., D. Zhu, X. Liao and Q. Yan, 2020. Effect of ECAP process and subsequent annealing on microstructure and properties of $\mathrm{Cu}-0.25 \mathrm{Se}$ 0.25Te Alloy. J. Electron. Mater.

Kuhlmann-Wilsdorf, D., 1996. Dislocation cells, redundant dislocations and the leds hypothesis. Scripta Mater., 34: 641-650. DOI: 10.1016/13596462(95)00567-6

Kyungjin Kim, D.Y.Y. and J.W. Yoon, 2010. Microstructural evolution and its effect on mechanical properties of commercially pure aluminum deformed by Equal Channel Angular Extrusion (ECAE) via routes A and C. Mater. Sci. Eng. A, 527: 7927-7930. DOI: 10.1016/j.msea.2010.08.084

Li, J., W. Xu, X. Wu, H. Ding and K. Xia, 2011. Effects of grain size on compressive behaviour in ultrafine grained pure $\mathrm{Mg}$ processed by equal channel angular pressing at room temperature. Mater. Sci. Eng. A, 528: 5993-5998. DOI: 10.1016/j.msea.2011.04.045

Ma, Y., F.Y. Han, C. Liu and M.Z. Li, 2019. Microstructure, Texture evolution and mechanical properties of ECAP-processed ZAT522 magnesium alloy. Acta Metallurgica Sinica. 
Martynenkoa, N.S., E.A. Lukyanovaa, V.N. Serebryany, M.V. Gorshenkov and I.V. Shchetinin et al., 2018 Increasing strength and ductility of magnesium alloy WE 43 by equalchannel angular pressing. Mater. Sci. Eng. A, 712: 625-629.

DOI: $10.1016 /$ j.msea.2017.12.026

Miyamoto, H., K. Harada, T. Mimaki, A. Vinogradov and S. Hashimoto, 2008. Corrosion of ultra-fine grained copper fabricated by equal-channel angular pressing. Corros. Sci., 50: 1215-1220.

DOI: 10.1016/j.corsci.2008.01.024

Mostaed, E., M. Vedani, M. Hashempour and M. Bestetti, 2014. Influence of ECAP process on mechanical and corrosion properties of pure $\mathrm{Mg}$ and ZK 60 magnesium alloy for biodegradable stent applications. Biomatter, 4: e28283-e28283.

DOI: $10.4161 /$ biom. 28283

Nassef, A., S. Samy and W.H. El-Garaihy, 2015. Enhancement of mechanical properties for Al-Mg-Si alloy using equal channel angular pressing. Int. J. Mater. Metallurgical Eng., 9: 131-136.

Orlov, D., K. Ralston, N. Birbilis and Y. Estrin, 2011. Enhanced corrosion resistance of $\mathrm{Mg}$ alloy $\mathrm{ZK} 60$ after processing by integrated extrusion and equal channel angular pressing. Acta Materialia, 59: 6176-6186. DOI: 10.1016/j.actamat.2011.06.033

Priela, E., B. Mittelman, N. Trabelsi, Y. Cohen and Y. Koptiar et al., 2019. A computational investigation of equal channel angular pressing of molybdenum validated by experiments. J. Mater. Proc. Tech., 264: 469-485. DOI: 10.1016/j.jmatprotec.2018.09.032

Qiang, G., E. Mostaed, C. Zanella, Y. Zhentao and M. Vedani, 2014. Ultra-fine grained degradable magnesium for biomedical applications. Rare Metal Mater. Eng., 43: 2561-2566.

DOI: $10.1016 / \mathrm{S} 1875-5372(15) 60001-7$

Sabbaghianrad, S., S.A. Torbati-Sarraf and T.G. Langdon, 2018. An investigation of the limits of grain refinement after processing by a combination of severe plastic deformation techniques: A comparison of $\mathrm{Al}$ and $\mathrm{Mg}$ alloys. Mater. Sci. Eng. A, 712: 373-379. DOI: 10.1016/j.msea.2017.11.090

Segal, V., 2018. Review: Modes and processes of Severe Plastic Deformation (SPD). Materials, 11: 1-29. DOI: $10.3390 / \mathrm{ma} 11071175$

Shaeri, M., K. Karimi Taheri, A. Karimi Taheri and M.H. Shaeri, 2019. An investigation on microstructure evolution, mechanical properties and strain aging of $\mathrm{Mg}-1.8 \mathrm{Zn}-0.7 \mathrm{Si}-0.4 \mathrm{Ca}$ biomedical alloy processed by equal channel angular pressing. J. Mater. Eng. Perform., 28: 5207-5219.

DOI: $10.1007 / \mathrm{s} 11665-019-04218-5$
Song, D., C. Li, N. Liang, F. Yang and J. Jiang et al., 2019. Simultaneously improving corrosion resistance and mechanical properties of a magnesium alloy via equal-channel angular pressing and post water annealing. Mater. Design, 166: 1-14. DOI: 10.1016/j.matdes.2019.107621

Suresh, M., A. Sharma, A.M. More, R. Kalsar and A. Bisht et al., 2019. EFFECT of Equal Channel Angular Pressing (ECAP) on the evolution of texture, microstructure and mechanical properties in the Al-Cu-Li alloy AA2195. J. Alloys Compounds, 785: 972-983. DOI: 10.1016/j.jallcom.2019.01.161

Tong, L.B., M.Y. Zheng, X.S. Hu, K. Wu and S.W. $\mathrm{Xu}$ et al., 2010. Influence of ECAP routes on microstructure and mechanical properties of $\mathrm{Mg}$ Zn-Ca alloy. Mater. Sci. Eng. A, 527: 4250-4256. DOI: $10.1016 /$ j.msea.2010.03.062

Valiev, R.Z. and T.G. Langdon, 2006. Principles of equal-channel angular pressing as a processing tool for grain refinement. Progress Mater. Sci., 51: 881-981. DOI: 10.1016/j.pmatsci.2006.02.003

Wang, H., C. Ban, N. Zhao, Q. Zhu and J. Cui, 2019. Effective grain refinement of pure $\mathrm{Cu}$ processed by new route of equal channel angular pressing. Mater. Sci. Eng. A, 751: 246-252.

DOI: 10.1016/j.msea.2019.02.045

Yamashita, A., Z. Horita and T.G. Langdon, 2001. Improving the mechanical properties of magnesium and a magnesium alloy through severe plastic deformation. Mater. Sci. Eng. A, 300: 142-147. DOI: 10.1016/S0921-5093(00)01660-9

Yang, Z., A. Ma, H. Liu, D. Song and Y. Wu et al., 2019. Managing strength and ductility in AZ 91 magnesium alloy through ECAP combined with prior and post aging treatment. Mater. Characterization, 152: 213-222.

DOI: 10.1016/j.matchar.2019.04.022

Yuan, T., J. Jiang, A. Ma, Y. Wu and Y. Yuan et al., 2019. Imultaneously improving the strength and ductility of an Al-5.5Mg-1.6Li-0.1Zr alloy via warm multi-pass ECAP. Mater. Characterization, 151: 130-141. DOI: 10.1016/j.matchar.2019.03.043

Zhang, J., Z. Kang and F. Wang, 2016. Mechanical properties and biocorrosion resistance of the $\mathrm{Mg}$ Gd-Nd-Zn-Zr alloy processed by equal channel angular pressing. Mater. Sci. Eng., 68: 194-197. DOI: $10.1016 /$ j.msec.2016.05.118

Zhu, Y.T. and J. Huang, 2001. Properties and nanostructures of materials processed by SPD techniques. Los Alamos National Lab., NM (US). 